\title{
On the Long-run Neutrality of Demand Shocks
}

\author{
Wenjuan Chen* \\ Aleksei Netsunajev**
}

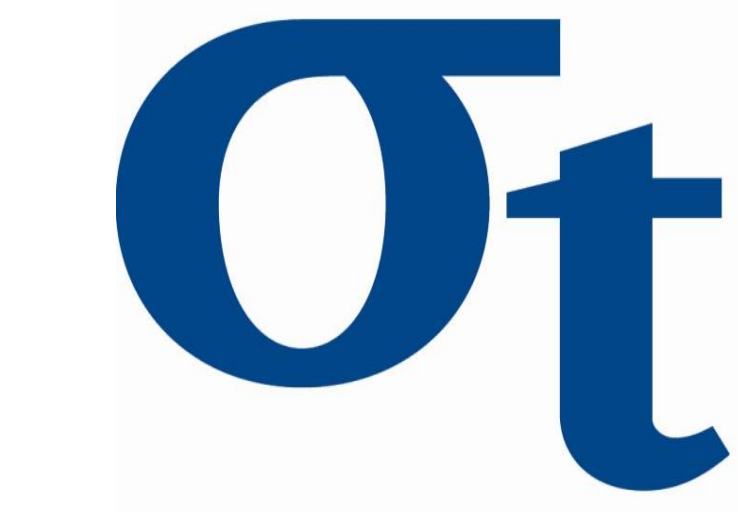

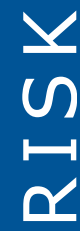

a

$\checkmark$

6

* Humboldt-Universität zu Berlin, Germany

This research was supported by the Deutsche Forschungsgemeinschaft through the SFB 649 "Economic Risk".

http://sfb649.wiwi.hu-berlin.de ISSN 1860-5664 


\title{
On the Long-run Neutrality of Demand Shocks
}

\author{
Wenjuan Chen \\ Humboldt Universität Berlin, Spaudauerstr. 1, 10178 Berlin, Germany \\ email: wenjuan.chen@fu-berlin.de \\ Aleksei Netšunajev \\ Freie Universität Berlin, Boltzmannstr. 20, 14195 Berlin, Germany \\ email: Aleksei.Netsunajev@fu-berlin.de
}

August 31, 2015

\begin{abstract}
Long run neutrality restrictions have been widely used to identify structural shocks in VAR models. This paper revisits the seminal paper by Blanchard and Quah (1989), and investigates their identification scheme. We use structural VAR models with smoothly changing covariances for identification of shocks. The resulted impulse responses are economically meaningful. Formal test results reject the long-run neutrality of demand shocks.

Key Words: Smooth transition VAR models, identification via heteroskedasticity, long-run neutrality, aggregate demand, aggregate supply JEL classification: C32
\end{abstract}

Support by the Deutsche Forschungsgemeinschaft through the CRC 649 'Economic Risk' is greatly appreciated. 


\section{Introduction}

In their seminal paper, Blanchard and Quah (1989) propose to identify demand and supply disturbances based on the assumption that the aggregate demand shocks have no long run effects on output. Long run neutrality restrictions have since been widely used to identify structural shocks in VAR models. Examples include Gali (1999) and Francis and Ramey (2005).

However, the assumption of long-run neutrality of aggregate demand shocks is not beyond doubt. Blanchard and Quah (1989) themselves raise concerns that this assumption might not be correct. Through capital accumulation or learning by doing, the demand disturbances can lead to longlasting effects on output. Recently, Keating (2013) finds that the aggregate demand shock had long-run effects on output in the pre-World War I economies.

In order to shed more light on this issue, in this paper we relax the longrun neutrality assumption on demand shocks, and instead use information from changes in volatility to identify shocks following a recently developed method by Lütkepohl and Netšunajev (2014). ${ }^{1}$ This method is advantageous to capture the volatility shifts in the data due to the Great Moderation. Combing the distinct relative variances with the intuition that the demand shocks push output and unemployment to opposite directions, we achieve identification of the demand and supply shocks via heteroskedasticity. The resulted impulse responses are similar to those by Blanchard and Quah (1989). However, the demand shocks' effects on output do not die out in the long run. A formal test further show that the long-run neutrality restriction is rejected by the data. These results suggest that supply shocks are not the only sources of permanent shifts in output.

\footnotetext{
${ }^{1}$ Other literature that use changes in volatility for identification include Rigobon (2003), Lanne and Lütkepohl (2008) and Bacchiocchi and Fanelli (2015).
} 


\section{Identification Strategies}

\subsection{Standard Structural Identification}

In this subsection, we first show how shocks in a structural VAR model are commonly identified. Consider the baseline VAR of order $p(\operatorname{VAR}(p))$ of the form:

$$
y_{t}=\nu+A_{1} y_{t-1}+\cdots+A_{p} y_{t-p}+u_{t},
$$

where $y_{t}=\left(y_{1 t}, \ldots, y_{K t}\right)^{\prime}$ is a vector of observable variables, the $A_{i}$ are $(K \times K)$ coefficient matrices, $\nu$ is a $(K \times 1)$ constant term and the $u_{t}$ are $K$-dimensional serially uncorrelated reduced form residuals with mean zero and covariance matrix $\Sigma_{u}$. Suppose we denote the structural residuals by $\varepsilon_{t}$. They can be obtained from the reduced form residuals $u_{t}$ by a linear transformation:

$$
u_{t}=B \varepsilon_{t} \quad \text { or } \quad \varepsilon_{t}=B^{-1} u_{t} .
$$

The matrix $B$ contains the instantaneous effects of the structural shocks on the observed variables.

To proceed with impulse response analysis or forecast error variance decomposition, one has to first identify the shocks based on certain economic assumptions. The standard approach is to impose restrictions on $B$ (or on objects incorporating $B$ ) to pin down the economic shocks of interest. These restrictions may be zero restrictions indicating that a specific shock does not have an instantaneous effect on a certain variable, or a restriction on the long-run effects of a structural shock. In the setup by Blanchard and Quah (1989), they are imposed on the matrix of long-run effects of structural shocks that is given by:

$$
\Xi_{\infty}=\left(I_{K}-A_{1}-\cdots-A_{p}\right)^{-1} B
$$

assuming that the inverse exists.

\subsection{Identification via Smoothly Changing Covariances}

This paper follows the recently developed approach by Lütkepohl and Netšunajev (2014) for identification of shocks. Instead of relying on the long run restric- 
tion by Blanchard and Quah (1989), we suppose that $u_{t}$ is a heteroskedastic error term with smoothly changing covariances:

$$
E\left(u_{t} u_{t}^{\prime}\right)=\Omega_{t}=\left(1-G\left(\gamma, c, s_{t}\right)\right) \Sigma_{1}+G\left(\gamma, c, s_{t}\right) \Sigma_{2}
$$

where $\Sigma_{1}$ and $\Sigma_{2}$ are distinct covariance matrices and $G\left(\gamma, c, s_{t}\right)$ is a transition function. The function depends on a parameter (vector) $\gamma$ and $c$ as well as a transition variable $s_{t}$. We model the transition in variances using a logistic transition function proposed by Maddala (1977) with time being the transition variable, i.e., $s_{t}=t$, so that we can capture endogenously the volatility changes in the data known as the Great Moderation.

$$
G(\gamma, c, t)=(1+\exp [-\exp (\gamma)(t-c)])^{-1}
$$

with $\exp (\gamma)>0$ for all values of $\gamma$.

The transition of the volatility from the covariance matrix $\Sigma_{1}$ to $\Sigma_{2}$ can be used for identification purposes. Consider the decomposition

$$
\Sigma_{1}=B B^{\prime} \text { and } \Sigma_{2}=B \Lambda B^{\prime},
$$

where $\Lambda=\operatorname{diag}\left(\lambda_{1}, \ldots, \lambda_{K}\right)$ is a diagonal matrix with positive diagonal elements. Apart from changes in sign of the columns of $B$ this decomposition is unique for a given ordering of the $\lambda_{i}$ if these quantities are all distinct (see Lütkepohl (1996, Section 6.1.2 (10)) or Theorem 7.6.4 in Horn and Johnson (2013)). The diagonal elements of the $\Lambda$ matrix can thus be interpreted as variances of structural shocks in the final regime relative to the initial regime. We refer to the smooth transition structural VAR model through the acronym ST-SVAR(p) with $p$ defining number of lags.

If the uniqueness conditions for $B$ are satisfied, any restrictions imposed on $B$ or $\Xi_{\infty}$ in a conventional SVAR framework become over-identifying and can be tested against the data. Various studies use likelihood ratio tests for this purpose. For that reason the model shown here is suitable to test formally the doubts on the long run neutrality of demand shocks expressed by Blanchard and Quah (1989). The fit of the model to the data will be discussed in the next section. 


\section{Empirical Analysis of Demand and Supply Shocks}

To analyze supply and demand shocks, we follow Blanchard and Quah (1989) and consider the following two variables: $y_{t}=\left(\Delta G N P_{t}, U_{t}\right)^{\prime}$. Where $\triangle G N P_{t}$ is the first differences in log GNP, and $U_{t}$ is the level of unemployment rate. Seasonally adjusted data are downloaded from the Federal Reserve Bank of Saint Louis. The sample period covers from 1970Q1 to 2007 Q4.

\subsection{Estimates of the ST-SVAR Model}

Table 1: Comparison of models for $y_{t}=\left(G N P_{t}, U_{t}\right)^{\prime}$

\begin{tabular}{l|ccc}
\hline \hline Model & $\log L_{T}$ & AIC & SC \\
\hline VAR(2) & -190.609 & 407.219 & 446.357 \\
ST-SVAR(2) & -155.280 & 346.561 & 400.752 \\
\hline
\end{tabular}

Notes: $L_{T}-$ likelihood function, AIC $=-2 \log L_{T}+2 \times$ no of free parameters, $S C=$ $-2 \log L_{T}+\log T \times$ no of free parameters.

The estimation of the ST-SVAR model is performed with the algorithm developed by Lütkepohl and Netšunajev (2014). We perform a grid search over parameters $c$ and $\gamma$, refining the grid in the neighborhood of the optimum. Table 1 compares some summary statistics of the ST-SVAR(2) model with those of the $\operatorname{VAR}(2)$ model. $^{2}$ Both the Akaike and Schwarz information criteria favor the choice of the ST-SVAR model.

Figure 1 shows the estimated transition function from the ST-SVAR model. The estimated transition takes place in 1983Q1, which fits the timing of the Great Moderation. Figure 2 shows the standardized residuals of the ST-SVAR(2) model. They seem to be much more homogeneous compared with those from the $\operatorname{VAR}(2)$ model shown in Figure 3. Bai and Perron (2003) test further shows no breaks in the variance. The ST-SVAR model seems to adequately fit the data.

\footnotetext{
${ }^{2}$ The lag length is chosen according to the Akaike information criteria.
} 
Figure 1: Estimated transition function of the ST-SVAR model

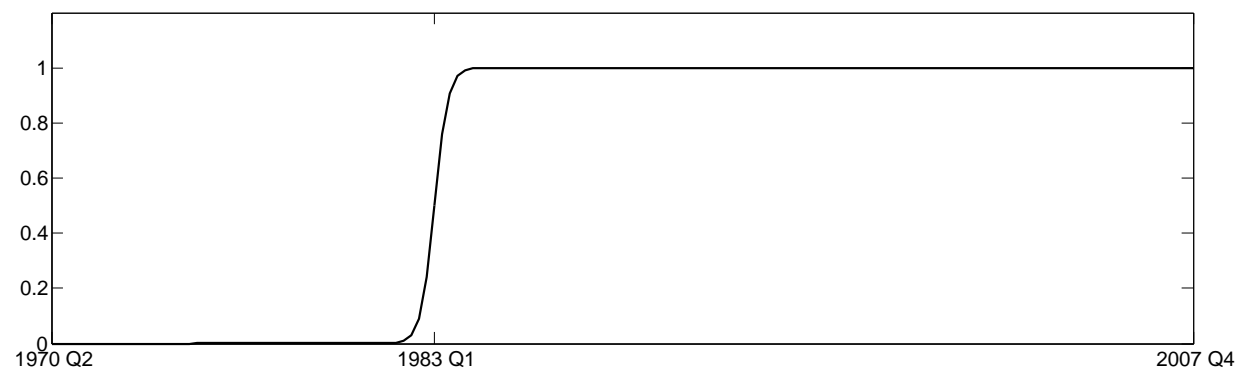

Figure 2: Standardized residuals of the ST-SVAR(2) model
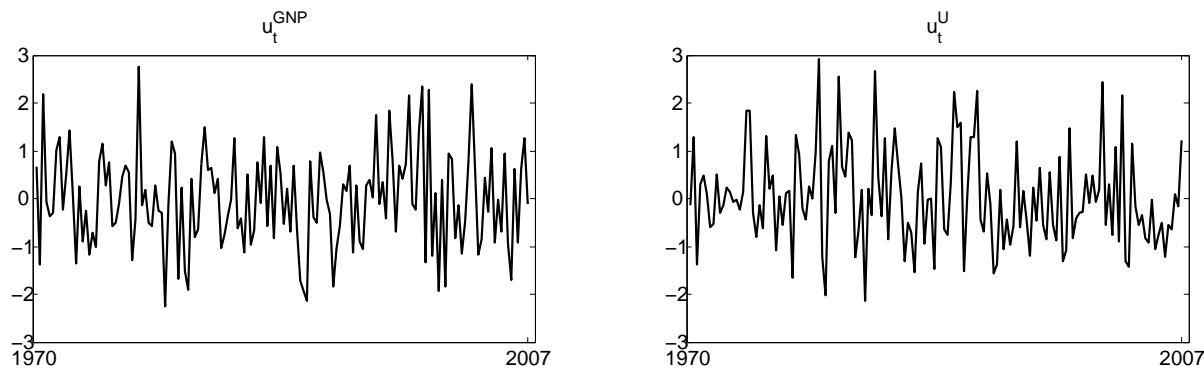

Figure 3: Standardized residuals of the $\operatorname{VAR}(2)$ model.
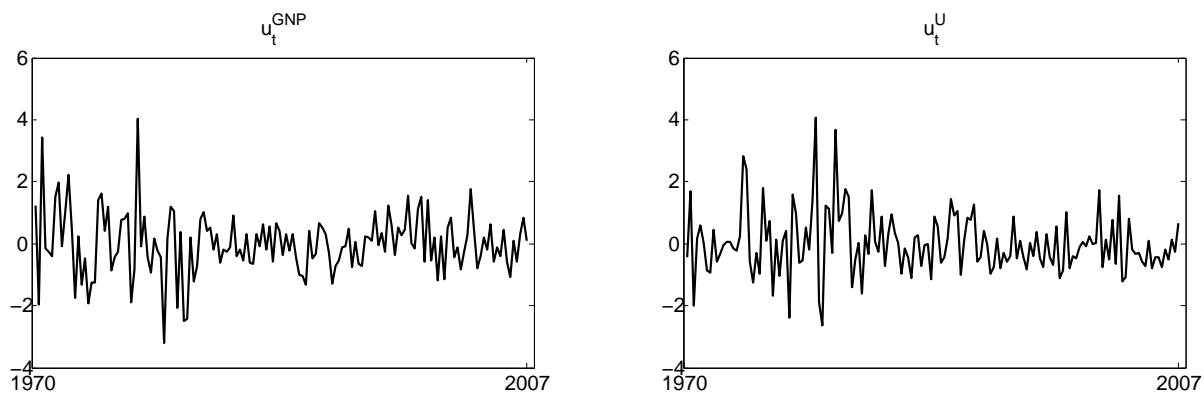

For identification of shocks, we need to check some estimated parameters of the ST-SVAR model. Table 2 presents the estimated relative variances. 
They are all below one, indicating that a change to the low volatility state occurs. The estimated variances look quite different, and the standard errors of the estimates are relatively low. The variances are about two standard errors apart from each other. Thus the data is informative on the two shocks, and they can be identified by the means of their changing variances.

Table 2: Estimates of relative variances of the unrestricted ST-SVAR(2) model

\begin{tabular}{l|rr}
\hline \hline parameter & estimate & std.dev. \\
\hline$\lambda_{1}$ & 0.142 & 0.039 \\
$\lambda_{2}$ & 0.450 & 0.152 \\
\hline
\end{tabular}

\subsection{Impulse Responses and the Test on the Long-run Re- striction}

Figure 4 shows the impulse responses of the higher volatility state that are resulted from the identification via changes in volatility. We label the first shock as the aggregate demand shock because its effects on output and unemployment go in the opposite directions, which is a stylized fact. In contrast, the responses of output and unemployment are both positive after an aggregate supply shock. The identified demand shocks have a humpshaped impact on both output and unemployment. After a positive supply shock, the output increases steadily for around 5 years and then stays at a plateau level. The response of the unemployment is initially positive but declines to zero over time. In general, our impulse responses are in line with those of Blanchard and Quah (1989), except that the impact of the demand shock on output seems not to decay to zero over time.

Since our impulse response analysis shows evidence against the long run restriction proposed by Blanchard and Quah (1989), we further test this restriction statistically. We estimate the ST-SVAR model with the identifying restriction imposed on the matrix of long run effects $\Xi_{\infty}$, making it lower triangular. We next perform the likelihood ratio test of the restric- 
Figure 4: Impulse responses of the higher volatility state
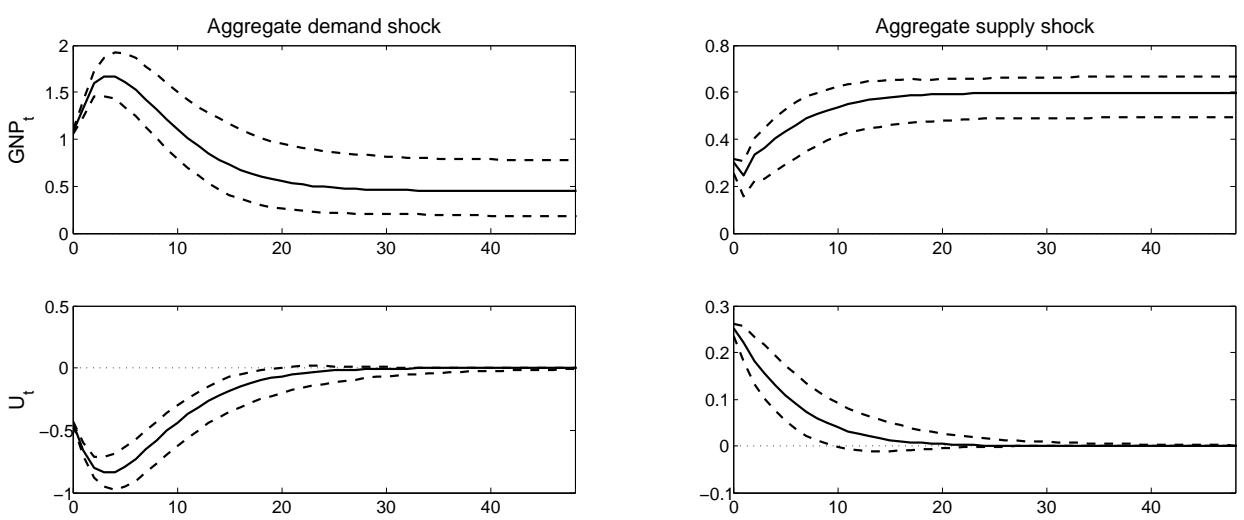

Notes: This graph shows the impulse responses of the higher volatility state obtained from the unrestricted ST-SVAR model. Solid lines - point estimates, dashed lines 68\% confidence bands based on 1000 bootstrap replications.

tion, obtaining the test statistic of 5.389 and the p-value of 0.020. This is strong evidence against the long run neutrality assumption of the demand shocks' effects on output. If the demand shocks are not long-run neutral, permanent and transitory shocks identified à la Blanchard and Quah (1989) are actually mixtures of different structural shocks.

\section{Conclusions}

This paper revisits the structural VAR model proposed in the seminal paper by Blanchard and Quah (1989). Using a new identification method following Lütkepohl and Netšunajev (2014), we are able to identify shocks without relying on the long run neutrality assumption of demand shocks. Our impulse response are economically interpretable. The estimated long run effects of the demand shocks on output do not die out over time. Formal test results on the long run restriction also provide evidence against it. Our findings suggest that demand shocks may result in permanent changes in output. It is recommendable for policy makers to take this into account for optimal 
policy decisions.

\section{References}

Bacchiocchi, E., And L. Fanelli (2015): "Identification in Structural Vector Autoregressive models with structural changes, with an application to US monetary policy," Oxford Bulletin of Economics and Statistics.

BAI, J., And P. Perron (2003): "Computation and analysis of multiple structural change models," Journal of Applied Econometrics, 18(1), 1-22.

Blanchard, O. J., And D. Quah (1989): "The dynamic effects of aggregate demand and supply disturbances," The American Economic Review, 79(4), 655-673.

Francis, N., And V. A. RAmey (2005): "Is the technology-driven real business cycle hypothesis dead? Shocks and aggregate fluctuations revisited," Journal of Monetary Economics, 52(8), 1379-1399.

Gali, J. (1999): "Technology, Employment, and the Business Cycle: Do Technology Shocks Explain Aggregate Fluctuations?," The American Economic Review, 89(1), 249-271.

Horn, R. A., And C. R. Johnson (2013): Matrix Analysis. Cambridge University Press, 2nd edn.

Keating, J. W. (2013): "What do we learn from Blanchard and Quah decompositions of output if aggregate demand may not be long-run neutral?," Journal of Macroeconomics, 38, 203-217.

Lanne, M., And H. LÜtKepohl (2008): "Identifying Monetary Policy Shocks via Changes in Volatility," Journal of Money, Credit and Banking, 40, 1131-1149.

Lütкepohl, H. (1996): Handbook of Matrices. John Wiley \& Sons, Chichester. 
Lütkepohl, H., And A. NetŠunajev (2014): "Structural Vector Autoregressions with Smooth Transition in Variances - The Interaction Between U.S. Monetary Policy and the Stock Market," Sfb 649 discussion papers, Sonderforschungsbereich 649, Humboldt University, Berlin, Germany.

Maddala, D. S. (1977): Econometrics. McGraw-Hill, New York.

Rigobon, R. (2003): "Identification through heteroskedasticity," Review of Economics and Statistics, 85, 777-792. 


\section{SFB 649 Discussion Paper Series 2015}

For a complete list of Discussion Papers published by the SFB 649, please visit http://sfb649.wiwi.hu-berlin.de.

001 "Pricing Kernel Modeling" by Denis Belomestny, Shujie Ma and Wolfgang Karl Härdle, January 2015.

002 "Estimating the Value of Urban Green Space: A hedonic Pricing Analysis of the Housing Market in Cologne, Germany" by Jens Kolbe and Henry Wüstemann, January 2015.

003 "Identifying Berlin's land value map using Adaptive Weights Smoothing" by Jens Kolbe, Rainer Schulz, Martin Wersing and Axel Werwatz, January 2015.

004 "Efficiency of Wind Power Production and its Determinants" by Simone Pieralli, Matthias Ritter and Martin Odening, January 2015.

005 "Distillation of News Flow into Analysis of Stock Reactions" by Junni L. Zhang, Wolfgang K. Härdle, Cathy Y. Chen and Elisabeth Bommes, January 2015.

006 "Cognitive Bubbles" by Ciril Bosch-Rosay, Thomas Meissnerz and Antoni Bosch-Domènech, February 2015.

007 "Stochastic Population Analysis: A Functional Data Approach" by Lei Fang and Wolfgang K. Härdle, February 2015.

008 "Nonparametric change-point analysis of volatility" by Markus Bibinger, Moritz Jirak and Mathias Vetter, February 2015.

009 "From Galloping Inflation to Price Stability in Steps: Israel 1985-2013" by Rafi Melnick and till Strohsal, February 2015.

010 "Estimation of NAIRU with Inflation Expectation Data" by Wei Cui, Wolfgang K. Härdle and Weining Wang, February 2015.

011 "Competitors In Merger Control: Shall They Be Merely Heard Or Also Listened To?" by Thomas Giebe and Miyu Lee, February 2015.

012 "The Impact of Credit Default Swap Trading on Loan Syndication" by Daniel Streitz, March 2015.

013 "Pitfalls and Perils of Financial Innovation: The Use of CDS by Corporate Bond Funds" by Tim Adam and Andre Guettler, March 2015.

014 "Generalized Exogenous Processes in DSGE: A Bayesian Approach" by Alexander Meyer-Gohde and Daniel Neuhoff, March 2015.

015 "Structural Vector Autoregressions with Heteroskedasticy" by Helmut Lütkepohl and Aleksei Netšunajev, March 2015.

016 "Testing Missing at Random using Instrumental Variables" by Christoph Breunig, March 2015.

017 "Loss Potential and Disclosures Related to Credit Derivatives - A CrossCountry Comparison of Corporate Bond Funds under U.S. and German Regulation" by Dominika Paula Gałkiewicz, March 2015.

018 "Manager Characteristics and Credit Derivative Use by U.S. Corporate Bond Funds" by Dominika Paula Gałkiewicz, March 2015.

019 "Measuring Connectedness of Euro Area Sovereign Risk" by Rebekka Gätjen Melanie Schienle, April 2015.

020 "Is There an Asymmetric Impact of Housing on Output?" by Tsung-Hsien Michael Lee and Wenjuan Chen, April 2015.

021 "Characterizing the Financial Cycle: Evidence from a Frequency Domain Analysis" by Till Strohsal, Christian R. Proaño and Jürgen Wolters, April 2015.

\section{SFB 649, Spandauer Straße 1, D-10178 Berlin http://sfb649.wiwi.hu-berlin.de}




\section{SFB 649 Discussion Paper Series 2015}

For a complete list of Discussion Papers published by the SFB 649, please visit http://sfb649.wiwi.hu-berlin.de.

022 "Risk Related Brain Regions Detected with 3D Image FPCA" by Ying Chen, Wolfgang K. Härdle, He Qiang and Piotr Majer, April 2015.

023 "An Adaptive Approach to Forecasting Three Key Macroeconomic Variables for Transitional China" by Linlin Niu, Xiu Xu and Ying Chen, April 2015.

024 "How Do Financial Cycles Interact? Evidence from the US and the UK" by Till Strohsal, Christian R. Proaño, Jürgen Wolters, April 2015.

025 "Employment Polarization and Immigrant Employment Opportunities" by Hanna Wielandt, April 2015.

026 "Forecasting volatility of wind power production" by Zhiwei Shen and Matthias Ritter, May 2015.

027 "The Information Content of Monetary Statistics for the Great Recession: Evidence from Germany" by Wenjuan Chen and Dieter Nautz, May 2015.

028 "The Time-Varying Degree of Inflation Expectations Anchoring" by Till Strohsal, Rafi Melnick and Dieter Nautz, May 2015.

029 "Change point and trend analyses of annual expectile curves of tropical storms" by P.Burdejova, W.K.Härdle, P.Kokoszka and Q.Xiong, May 2015.

030 "Testing for Identification in SVAR-GARCH Models" by Helmut Luetkepohl and George Milunovich, June 2015.

031 "Simultaneous likelihood-based bootstrap confidence sets for a large number of models" by Mayya Zhilova, June 2015.

032 "Government Bond Liquidity and Sovereign-Bank Interlinkages" by Sören Radde, Cristina Checherita-Westphal and Wei Cui, July 2015.

033 "Not Working at Work: Loafing, Unemployment and Labor Productivity" by Michael C. Burda, Katie Genadek and Daniel S. Hamermesh, July 2015.

034 "Factorisable Sparse Tail Event Curves" by Shih-Kang Chao, Wolfgang K. Härdle and Ming Yuan, July 2015.

035 "Price discovery in the markets for credit risk: A Markov switching approach" by Thomas Dimpfl and Franziska J. Peter, July 2015.

036 "Crowdfunding, demand uncertainty, and moral hazard - a mechanism design approach" by Roland Strausz, July 2015.

037 ""Buy-It-Now" or "Sell-It-Now" auctions : Effects of changing bargaining power in sequential trading mechanism" by Tim Grebe, Radosveta Ivanova-Stenzel and Sabine Kröger, August 2015.

038 "Conditional Systemic Risk with Penalized Copula" by Ostap Okhrin, Alexander Ristig, Jeffrey Sheen and Stefan Trück, August 2015.

039 "Dynamics of Real Per Capita GDP" by Daniel Neuhoff, August 2015.

040 "The Role of Shadow Banking in the Monetary Transmission Mechanism and the Business Cycle" by Falk Mazelis, August 2015.

041 "Forecasting the oil price using house prices" by Rainer Schulz and Martin Wersing, August 2015.

042 "Copula-Based Factor Model for Credit Risk Analysis" by Meng-Jou Lu, Cathy Yi-Hsuan Chen and Karl Wolfgang Härdle, August 2015.

043 "On the Long-run Neutrality of Demand Shocks" by Wenjuan Chen and Aleksei Netsunajev, August 2015.

\section{SFB 649, Spandauer Straße 1, D-10178 Berlin http://sfb649.wiwi.hu-berlin.de}

